\title{
Study on Profit of Participation Corporate in Loyalty Program Partnerships
}

\author{
Min Tian* and Xiaoting He \\ School of Economics and Management, Xi'an Technological University, Xi'an, 710021 \\ tianmin0@163.com624040675@qq.com
}

Keywords: Apparent Earnings; Latent Earnings; Loyalty Program Partnerships; Resource Sharing

\begin{abstract}
In recent years, the Loyalty Program Partnerships has got a lot of achievement, but what kind of benefit can get from the alliance need in-depth research. It is a very important topic to company whether they should join the Loyalty Program Partnerships, when should they practice join the alliance. How to share the benefits of the alliance from which have been generated. This problem about alliance has become the current international frontier and hot. This paper focuses on the benefit of company get from alliance, the apparent earnings and latent earnings are analyzed indepth, the conclusion give suggestions to corporate alliance strategy.
\end{abstract}

\section{Introduction}

Contemporary marketing has changed from consumer demand-oriented to humanistic-oriented era. Enterprises snatch limited resources by initial implementation of the loyalty program themselves, and then they cooperation with their competitors, they establishment of a common Loyalty Program Partnerships to achieve customer resource sharing, risk-sharing, the purpose of reducing the operating costs, and ultimately mutual benefit and win-win situation.

Today, Loyalty Program Partnerships exists in many forms in every corner, it can be divided into three joint operating models, these are alliance associate mode, independent operation mode and card mode, The most representative is "Sky Team" and "Star Alliance" in airline industry, "Xing yue Union" and China Southern Airlines" "Sky Pearl members club" is representative Loyalty Program Partnerships of hotel and airline industry together. As a new strategic alliance marketing, it is in order to attract consumers to join the alliance and unite several companies implement Loyalty Program Partnerships The same industry and different industries are all included. The consumers in Loyalty Program Partnerships can exchange points and then return as a profit-driven way to encourage consumers to long-term fixed enterprise consumption, then they becoming loyal customers. in a number of stable customer support, and there will be more companies to join, and gradually formed a cross-regional, cross-industry integration and consumer network, this scale can not only reduce the cost of customer acquisition and maintenance, but also attract many new customers to enter, form a fixed consumer groups, a portion of profits sustained by the scale of consumption converted into points and redeem final feedback to the consumer, to improve customer satisfaction and loyalty of purpose, compared to traditional loyalty program in terms of having greater integration advantage.

From a consumer perspective, perceived benefits, perceived convenience, perceived risk that is attributes affect consumer attitudes and consumption wishes to participate in the Loyalty Program Partnerships, and perceived convenience also have an impact on the perception of risk, subjective norms influence the willingness of consumers to participate in Loyalty Program Partnerships, and demographic variables affect the willingness of consumers to participate in different Loyalty Program Partnerships. Loyalty Program Partnerships make up the points before independence plan is flawed because each firm to launch its own loyalty program, customers have a lot of loyalty cards, but each one membership card points can only be redeemed on some of the things what is not attract customers becomes meaningless. Loyalty Program Partnerships was able to greatly improve customer satisfaction, so that customers can actively participate in exchange, was added to the program. 
From a business perspective, as a fast and flexible way to access complementary resources and skills that reside in other companies, a growing number of firms formed a strategic alliance [1]. What are the business benefits? These questions are more a lack of research; therefore, the present study will participate in corporate earnings Loyalty Program Partnerships depth research alliance strategy for the integration of enterprises to provide theoretical advice.

\section{Literature Review}

To realize the Loyalty Program Partnerships which will bring benefits to the enterprise, we can learn from enterprises to establish a strategic alliance related literature, to understand what are the benefits of strategic alliances, how allocation enterprises income in strategic alliances. These studies can help us more in-depth analysis of Loyalty Program Partnerships.

Xiao ni Cong, Shi ping Li and Yi Cui (2014) find that the implementation of the revenue sharing mechanism can improve the performance of airline alliance members. The level of performance is closely related to the revenue sharing coefficient, the substitution relationship between airlines and the ratio of operating costs in the domestic and international routes. In addition, the numerical results determine that the effects of different parameters on the performances of the airline alliance members are different under the revenue sharing mechanism[2]. Shao bai Chen, Man Zhang and Zhao di $\mathrm{Hu}$ (2015) propose weighted cooperative game problem, they discuss the rules to form a feasible coalitional structure in a weighted cooperative game. In order to maximize gain, a subset of players spontaneously forms a primary coalition with the weighted averaged maximum gain. The remaining players spontaneously form a secondary coalition with the weighted averaged maximum revenue and so on until all players have joined the coalition. The conclusion shows that the rights and interests of players are from the competition among individuals and the overall maximum revenue reflects the cooperation of all players [3]. Zhi ying Liu and Dan dan Wang (2013) find that the all-league not only maximizes the benefits of alliance, but also maximizes the benefits of single enterprise. And they dish the profit distribution mechanism in the all league and half-league by the status of the upstream and downstream enterprises and the proportion of technological innovations [4]. Dan Hu and Jing dong Yan (2013) propose that the profit allocation in regional technology transfer alliance is a consequence of gaming process among the participants. The governments and technology agencies should undertake the technology transfer market value assessment and market regulation to improve a sustained and stable cooperation in technology transfer between the technology supplier and demander. The transfer profit can realize by the ways of lump sum payment or payment by instalments, royalty payment, mixed royalty payment, production investment payment, service investment payment and mixed payment [5]. Shao hua Lu and Zhi xiang Tao (2004) study the strategy of profit allotting among virtual enterprise by learning of the bargaining between two members. They point out that profit allotting is realized through trades among members. The relation between members' demand price elasticity and the price and quantity they accept in trading, and that between member's materials consuming rate and their price-bearing capability, have been studied. They prove that bargain and non-cooperate game will lead to $\mathrm{X}$-inefficiency, and they point out that cooperation game works the best, but less stably [6]. Jia hua Gan etc.(2014) analyze the differences between the choice of income distribution mode and income structure of member companies on the basis of the concept and type of small and mediumsized logistics enterprises alliance and the purpose and connotation of income distribution, according to three types of small and medium-sized logistics enterprise alliance [7]. Hong Gong and Wen Huo (2014) put forward some suggestions to the industry technology innovation strategic alliance revenue allocation mechanism [8]. Hokey Min and Seong-Jong Joo(2016) attempt to assess the impact of airline alliances on the global airline's competitiveness using DEA and its post-hoc analyses and then investigate whether the airline's participation in code sharing practices can be developed into its viable strategic weapon[9]. Bo Wang (2015) applies orthogonal projection to the profit allocation of a technical alliance based on traditional profit allocation methods. This 
distribution method is based on the weight coefficient of the first four profit allocation projects, and split the four different profit allocation methods into a comprehensive profit distribution plan [10].

\section{The Profit of Participation Corporate in Loyalty Program Partnerships}

What benefits can be obtained from the Loyalty Program Partnerships for participate corporate? It is very important question to construct the alliance and implement the alliance. Corporate earnings obtained from the Loyalty Program Partnerships can be divided into two types, namely apparent earnings and latent earnings. As shown the Fig. 1.

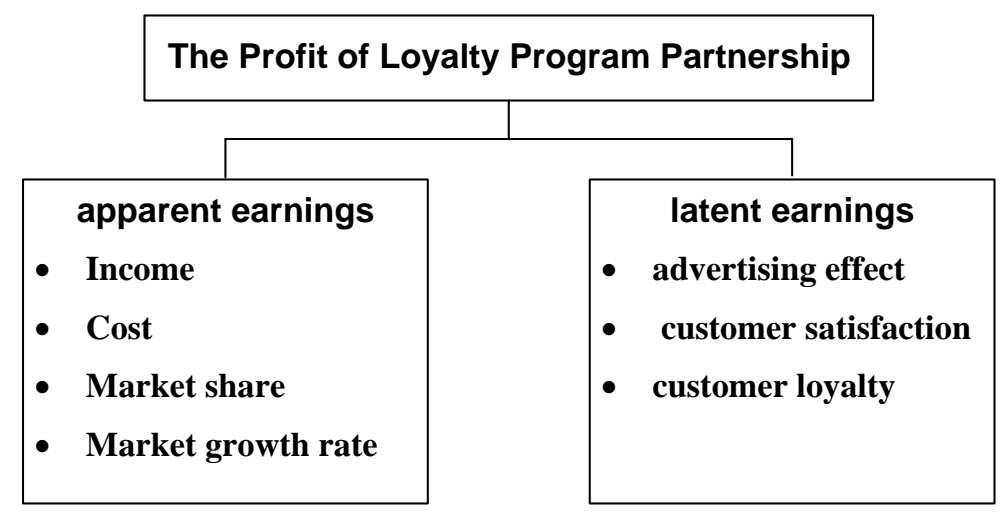

Figure 1. Profit of loyalty program partnership

The Fig. 1 shows that apparent earnings include four aspects: corporate income, corporate cost, market share and market growth rate. The latent earnings include three aspects: advertising effect, customer satisfaction and customer loyalty.

Apparent Earnings. The participant corporate can obtain from the Loyalty Program Partnerships, it is why the corporate join the alliance. Firstly, it will increase the income of the corporate through share the customer from other corporate in the alliance. For example, in the airline industry Loyalty Program Partnerships, it can take advantage of frequent flyer global seamless, uninterrupted services to attract new customers. With respect to the individual airlines, the alliance greatly enhanced the competitiveness of competing for customers. The loyalty of the old customers and the increase of new customers, they all bring more revenue and more competitive ticket prices to all enterprises in the alliance. Secondly, the alliance will decrease the cost of the corporate. Cost is an important source of competitive advantage, almost all companies focus on cost as one of the key management content. The traditional cost management focus on internal production process in a variety of cost, starting from the procurement and end in sales, this kind of management thinking is a narrow, relatively simple methods, it is poor management effectiveness. Faced with fierce competition in the market, as an important part of modern management accounting cost management, we must abandon outdated thinking and practices, in terms of cost to help enterprises enhance competitive advantage. Wherein a feasible way is to introduce the concept of a strategic alliance thinking in terms of cost management activities, breaking the boundaries between business and industry, business to business, enterprise technology, cost, management, and other departments in different value chains range within seek the optimal combination and dynamic allocation of resources, to cooperate with a shared view of the strategic alliance, innovation modern cost management thinking and methods. In the airline industry loyalty program partnerships, the company reduce the direct operating costs through reorganize the aircraft, reduce staff and so on. Code-sharing alliance between airlines can make a route exists on the surface, but in fact does to operate the line by other airlines, thereby effectively saving fuel costs, staff costs and other variable costs, in order to reduce direct operating cost variable. Thirdly, after joining the Loyalty Program Partnerships, the company's market share will increase. Sharing enterprise resource is one of significant factor to attract the corporate joining the alliance, in one hand, to the other companies within the alliance by means of customer base, maintain existing customers through the advantages 
of coalition loyalty programs and attract new customers to join, on the other hand but also with a strong advantage leading international scale and bargaining, management and service alliance to further expand market share, enhance the management level, reduce costs and increase revenue. Foreign companies need to join the alliance through the integration of domestic enterprises to join further open the Chinese market, the share of domestic resources of members. Therefore, we believe that the sharing of resources on companies added Loyalty Program Partnerships mainly to expand the sharing of resources for customers and market share. Fourthly, it will bring increasing of the market growth rate when company joins the alliance. To join the alliance will bring more business competitive advantage, this competitive advantage to enable enterprises to win more market, so the market growth rate will be raised. At the same time, to join the alliance reduced competition among enterprises, enhance cooperation and win-win results that will bring sustainable development of enterprises, market growth will be sustained increase.

Latent Earnings. There are three aspects latent earnings from the Loyalty Program Partnerships. Firstly, after joining the Alliance, marketing and advertising information is more diversified; the advertising content has been expanded than former alliance. On the one hand, companies can make use of the advantages of advertising alliance, in order to expand advocacy efforts, on the other hand, other companies mention the alliance enterprise information when they are advertising, which joined the companies also have some spillover effect. Therefore, the Loyalty Program Partnerships advertise information have some spillover effect to all of joining companies, this kind of advertising spillover effect is an important aspect of the business benefits gained from Loyalty Program Partnerships. Secondly, Companies added the alliance can bring to customers more choices, more redeem ways and means, it can also be selected when customer in the choice of products. The points can be used in other businesses, so it will enhance customer satisfaction. At the same time, joining the Alliance, especially large international coalition, which will also enable the customer perceived value can be improved, and therefore enhance customer satisfaction. Thirdly, Loyalty Program itself is a marketing tool used to improve customer loyalty, as Loyalty Program Partnerships plans to extend program, better obtain customer loyalty. On the one hand, customers accumulate points in the alliance; will be linked to long-term customers and enterprises. After adding Loyalty Program Partnerships, there are more choices in choosing products and redeem ways, which will win more customer loyalty, and therefore, customer loyalty is to bring business alliance integral another latent benefit.

\section{Conclusion}

It is an important research topic that the company benefits from the Loyalty Program Partnerships. Analyzing deeply on the benefit of joined company in alliance, it conclude that the company's earnings performance in two ways from alliance. On the one hand, it is the apparent earnings from the Loyalty Program Partnerships, that is reflected in the financial performance, including increased revenue, reduce costs, increase market share and market growth rate continues to increase. On the other hand it showed latent earnings, that is, cannot be reflected in the financial performance, but does business performance can bring help, the spillover effect is mainly reflected in the advertising alliance, enhance customer satisfaction and loyalty. These studies have management suggestion to enterprise alliance strategy.

\section{Acknowledgements}

This paper is supported by National Natural Science Foundation for Youth of Shaanxi Province Science and Technology Hall (2013JQ9006), Social Science Foundation of Shaanxi Province (2015R018) and Foundation of Ministry of Education of China for Youth (13YJC630014) 


\section{References}

[1] J.H. Dyer, P. Kale and H. Singh: How to make strategic alliance work, J. MIT Sloan Management Review. 42(2001) 36-43

[2] X.N. Cong, S.P. Li and Y. Cui Decision models for airline alliance network under revenue sharing mechanism, J. Industrial Engineering Journal. 17 (2014) 103-110

[3] S.B. Chen, M. Zhang and Z.D. Hu Feasible coalitional structure and profit distribution in a weighted cooperative gam, J. Journal of Wuhan University of Science and Technology. 38 (2015) 77-80

[4] Z.Y. Liu and D.D. Wang Analysis of profit allocation in technology innovation alliance game model of industrial chain, J. Canadian Social Science. 9(2013) 62-67

[5] D. Hu and J.D. Yan Profit allocation and realization in regional technology transfer alliance based on game theory, J. Advanced Materials Research. 834(2014) 2011-2016

[6] S.H. Lu and Z.X. Tao Profit-allotting game in virtual enterprise, J. Journal of Industrial Engine e airing Management. 18(2004) 65-68

[7] J.H. Gan, J.W. Wang, Z. Chen and J. Zhao Quality-oriented on income distribution of small and medium-sized logistics enterprises alliance, J. Technology Economy and Management Research. 10(2014) 38-43

[8] H. Gong and W. Huo The proposal about profit sharing mechanism of industrial technology innovation alliance, J. Science and Technology Progress and Policy. 31(2014) 54-57

[9] H. Min and S.J. Joo A comparative performance analysis of airline strategic alliances using data envelopment analysis, J. Journal of Air Transport Management. 52(2016) 99-110

[10]B. Wang. Information Technology and Mechatronics Engineering Conference (Chongqing, China, March 28-29, 2015). Vol. 1, p.33-36. 